\title{
Caracterizações de convexidade para polígonos simples
}

\author{
Luciano André $\quad$ Rogério de Aguiar
}

\begin{abstract}
Resumo
Na educação básica são apresentadas algumas definições de polígonos convexos de maneira sucinta, de modo a fornecer caracterizações desse tipo de polígono para, em seguida, desenvolver os tópicos de geometria plana restrigindo a esta categoria. Em geral não abordam polígonos simples não convexos nesse nível escolar. Também não é comum discutir sobre a equivalência entre as diversas de suas caracterizações. O objetivo deste artigo é demonstrar resultados sobre convexidade, que ampliam as noções sobre tal assunto na educação básica, estendendo a teoria dos polígonos simples para o caso não convexo. Uma vez feito o desenvolvimento teórico, são sugeridas formas de apresentação da convexidade no ensino básico usando elementos visuais e a intuição. Serão discutidas as diferentes formas de caracterizar os polígonos convexos e as dificuldades que surgem ao tentar abordar os não convexos. Os procedimentos metodológicos utilizados foram a pesquisa qualitativa na forma de pesquisa bibliográfica e documental. Como resultado reúnem-se em um único texto diversas proposições sobre convexidade que se encontravam dispersas na literatura, usando para tal objetivo uma axiomática adequada ao ensino de geometria na educação básica, qual seja, a axiomática da régua graduada e do transferidor.
\end{abstract}

Palavras-chave: Polígonos Simples; Geometria Dedutiva; Convexidade.

\section{Abstract}

In basic education some types of definitions of convex polygons are presented succinctly, in order to provide characterizations of this type of polygon and then to develop the topics of flat geometry restricting to this category. In general, they do not address simple non-convex polygons at this school level. Nor is it common to discuss the equivalence between the various of his characterizations. The purpose of this article is to demonstrate results on convexity, which broaden the notions about such subject in basic education, extending the theory of simple polygons to the nonconvex case. Once the theoretical development is done, we suggest ways of presenting convexity in basic education using visual elements and intuition. We will discuss the different ways of characterizing convex polygons and the difficulties that arise when trying to approach nonconvex polygons. The methodological procedures used were the qualitative research in the form of bibliographic and documentary research. As a result, several propositions about convexity that are scattered in the literature are gathered together in a single text, using for that purpose a framework adequate to the teaching of geometry in basic education, that is, the framework of the graduated ruler and the protractor. 
Keywords: Simple Polygons; Deductive Geometry; Convexity.

\section{Introdução}

A visualização e a intuição em geometria são sem dúvida os maiores aliados do professor do ensino fundamental e médio em suas aulas. Algumas justificativas dos enunciados da geometria nesse nível são obtidas por meio dos desenhos, de um conjunto de definições, ou de resultados que são apresentados sem demonstrações [7]; [8]; [13]; [16]. Uma explicação para tal forma de apresentação é que não é adequado na escola básica focar no formalismo, pois segundo Leivas o ensino da geometria na escola básica deve privilegiar "outras dimensões consideradas essenciais para o desenvolvimento de um pensamento geométrico, apoiado, por exemplo, no tripé imaginação, intuição e visualização [...]" [9, p18]. Assim, aconselha-se ao educador fazer demonstrações de teoremas em casos de importância destacada, e, dependendo do nível de complexidade, pode-se deixar de seguir rigorosamente o roteiro formal do método axiomático, para que sejam privilegiados os aspectos visuais. A ideia que permeia o ensino básico é clareza e não o rigor lógico. Abre-se mão desse em detrimento daquele com intuito de aproximar a geometria da realidade e de suas aplicações práticas. Para, porém, que o professor cumpra adequadamente seu papel, suas aulas devem ter por base um modelo de geometria dedutiva adequado a uma transposição didática, do qual o educador tenha conhecimento pleno. Os modelos de geometria à base da régua graduada e do transferidor, resultado de extensas discussões pedagógicas no século passado, são os preferidos entre os pesquisadores em educação matemática no mundo como instrumento de ensino da geometria dedutiva. As definições e resultados obtidos neste artigo tomaram por base o modelo axiomático constante do livro Geometria euclidiana plana e construções geométricas dos autores Eliane Quelho Frota Rezende e Maria Lúcia Bontorim de Queiroz [18], que por sua vez fora baseado na axiomática do School Mathematics Study Groups (SMSG). O SMSG foi um grupo de estudos para modernização do ensino básico de matemática nos Estados Unidos na década de 1960. Maiores informações sobre o trabalho desenvolvido por esse grupo podem ser obtidas no livro Geometry, Student's Text, Part I, Unit I3. de Frank B. Allen [1]. O modelo criado pelo SMSG usa axiomas de medida de segmentos e ângulos, substituindo a régua não graduada e o compasso euclidianos pela régua graduada e o transferidor. O desenvolvimento das ideias e as demonstrações dos resultados básicos associados a nossa discussão, dentro do contexto axiomático supracitado, podem ser consultados na dissertação "Convexidade em figuras geométricas planas" de Luciano do N. André [2]. A geometria dedutiva no ensino fundamental e médio oportuniza o contato e a identificação completa de seus elementos para as figuras geométricas mais simples: os triângulos, os polígonos simples convexos e o círculo. Portanto, podemos afirmar que a geometria dedutiva elementar, no contexto das figuras geométricas planas limitadas, é uma teoria sobre a convexidade. Nesses casos é cômodo identificar interior e exterior, perímetro, área e ângulos das figuras. No desenvolvimento de um curso introdutório de geometria axiomática, tal como no livro Geometria euclidiana plana de João Lucas Marques Barbosa [3], à medida em que as figuras convexas vão sendo obtidas formalmente, os exercícios vão surgindo para os casos não convexos, cuja resolução é feita na maioria dos casos apelando-se para os desenhos e a intuição do leitor. Neste contexto, o aluno interessado questiona-se sobre o interior do polígono, ângulos e outras propriedades para os casos não convexos. As dificuldades teóricas começam a surgir quando consideramos as figuras não convexas limitadas por polígonos simples. Dentre essas dificuldades destacamos duas delas, que iremos discutir nesse artigo:

1. Inexistência de ângulos reflexos. Pelo menos um ângulo interno de um polígono simples não convexo tem medida reflexa, i.e., $360^{\circ}-\alpha$, com $0^{\circ}<\alpha<180^{\circ}$. Portanto, há a necessidade 
no contexto dedutivo supracitado de se fazer uma ampliação da noção de ângulo para o seu adequado tratamento. Essa necessidade surge porque a medida de ângulos apresentada no modelo axiomático considerado é a medida padrão, $0^{\circ}<\alpha<180^{\circ}$, que corresponde ao uso do transferidor de meia-lua.

2. Interior do polígono simples não convexo. Neste caso a determinação do interior do polígono simples não convexo não é imediata como no caso convexo, que é uma intersecção de semiplanos.

Para compreendermos melhor os polígonos simples não convexos, iremos estudar várias caracterizações dos polígonos simples convexos. Com isso obteremos condições necessárias e suficientes para que um polígono seja convexo, condições essas que serão designadas como sendo as "Definições de Polígono Convexo". Identificaremos os polígonos não convexos como aqueles que não satisfazem as referidas condições. A inspiração para o estudo com essa abordagem teve início nos artigos da Revista do Professor de Matemática (RPM) intitulados " A soma dos ângulos (internos ou externos) de um polígono (convexo ou não) e "Qual é Mesmo a Definição de Polígono Convexo?" de Elon Lages Lima publicados na RPM 19 [10] e RPM 21 [11] colecionados no livro Matemática e ensino do mesmo autor [12]. A convexidade para polígonos convexos acaba por ser a chave para os alunos e professores entenderem melhor no contexto dedutivo os polígonos simples em geral. Em uma segunda etapa, pode-se avançar um pouco mais no estudo das figuras convexas e considerar a convexidade de figuras convexas limitadas quaisquer, conforme apresentado no Capítulo 5 da já referenciada dissertação [2].

Apropriando-se de elementos visuais, estimulando a imaginação e a intuição, o professor do ensino fundamental e médio utiliza muitas dessas caracterizações em sala de aula. Justificar que um polígono simples é convexo porque não tem reentrâncias ou porque todas as retas que contêm os lados são retas de apoio são exemplos de algumas atividades comuns entre os professores que ensinam geometria neste nível. Perguntar-se por que essas e outras noções sobre convexidade em polígonos são equivalentes é algo natural. A maioria dos livros de geometria, independentemente do nível, não trata de demonstrar a equivalência de tais caracterizações.

O objetivo deste artigo é apresentar e demonstrar resultados sobre convexidade que ampliam as noções vistas na educação básica, visando estender de forma natural os resultados e definições sobre polígonos convexos que são abordados nesse nível educacional. Embora não sendo inéditos os resultados aqui expostos, são apresentados de maneira concisa e encadeada, de modo a tornar o assunto mais atraente seguindo uma axiomática preestabelecida. Portanto, a novidade não está nos resultados e sim na forma de apresentação, reunindo diversas proposições dispersas na literatura e colocando-as em um encadeamento lógico. Permeia na discussão dos resultados a noção de fecho convexo, que pode ser aproveitada na apropriação do conceito de convexidade por meio da intuição. O significado que damos à palavra intuição é o mesmo discutido em [9] ,

"Considero intuição um processo de construção de estruturas mentais para a formação de um determinado conceito matemático, a partir de experiências concretas do indivíduo com um determinado objeto. O conceito deve ser formado de forma reflexiva, consciente, produzindo sentimento de certeza a partir da autoevidência [9, p21]."

Seguindo esse preceito, apresentamos na última seção deste artigo ideias sobre convexidade para 
polígonos simples, com potencial de aplicação nas aulas, usando a noção de fecho convexo e o geoplano. Outras noções intuitivas sobre convexidade também são apresentadas.

\section{Polígonos simples: primeiros resultados}

Iniciamos esta seção revendo a definição de ângulo, medida de ângulo e suas generalizações.

Definição 1 (Ângulo). Um ângulo é uma união de duas semirretas que têm a mesma origem, mas não estão contidas na mesma reta.

Os postulados 8 e 9 de [18] ensinam-nos como medir ângulos: $\mathrm{A}$ cada ângulo $\angle A B C$ corresponde um número real $\alpha$ entre 0 e 180. Reciprocamente, dada uma semirreta $\overrightarrow{B A}$ e $\mathcal{H}$ um semiplano da reta $\overleftrightarrow{B A}$, existe uma única semirreta $\overrightarrow{B C} \operatorname{com} C$ em $\mathcal{H}$ tal que $m(\angle A B C)=\alpha$. Na Figura 1 temos um exemplo quando $\alpha=74^{\circ}$. Chamaremos essa medida, por motivos que ficarão claros na sequência, de medida padrão do ângulo $\angle A B C$.

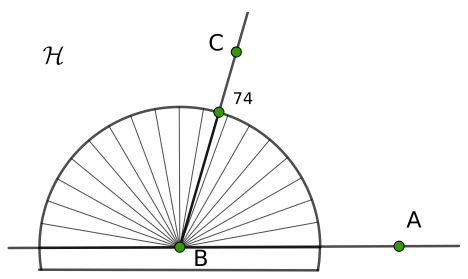

Figura 1: Medida do ângulo $\angle A B C$.

Os ângulos da Definição 1 são chamados ângulos próprios. Destacando os raios inicial e final, temos um ângulo orientado. Permitindo que os lados inicial e final possam ser coincidentes ou opostos, obtemos os ângulos de medida $0^{\circ}$ e $180^{\circ}$, chamados ângulo nulo e ângulo raso, respectivamente. Essa é a nossa primeira extensão da noção de medida de ângulo.

Definição 2 (Interior do ângulo). Dizemos que o ponto $P$ está no interior do ângulo próprio $\angle A B C$ ou é ponto interior do ângulo próprio $\angle A B C$ se os pontos $P$ e $A$ estiverem do mesmo lado da reta $\overleftrightarrow{B C}$ e os pontos $P$ e $C$ estiverem do mesmo lado da reta $\overleftrightarrow{B A}$

Segue da Definição 2 que o interior do ângulo próprio $\angle A B C$ é uma intersecção de dois semiplanos abertos, a saber: o determinado pela reta $\overleftrightarrow{B A}$ que contém o ponto $C$ e o determinado pela reta $\overleftrightarrow{B C}$ que contém o ponto $A$. Não se define interior do ângulo nulo e nem do ângulo raso, conforme (LEE, 2013, p95). O exterior do ângulo próprio $\angle A B C$ é o conjunto dos pontos do plano que não pertencem ao ângulo $\angle A B C$ e nem ao seu interior.

A um ângulo próprio podemos associar dois tipos de medida: a medida padrão $\alpha$, tal que $0^{\circ}<\alpha<$ $180^{\circ}$ e outra dada por $360^{\circ}-\alpha$, chamada de medida reflexa do $\angle A B C$.

Voltaremos a falar sobre a medida reflexa na sequência. Para o que segue precisamos de duas importantes definições. 
Definição 3. Sejam $A_{1}, A_{2}, \cdots, A_{n}$, com $n \geq 3$, uma sequência de pontos distintos no plano. Chama-se poligonal o conjunto formado pelos segmentos $A_{1} A_{2}, A_{2} A_{3}, \cdots, A_{n-1} A_{n}$. Acrescentando o segmento $A_{n} A_{1}$ a poligonal é dita ser fechada. Uma poligonal fechada será um polígono simples se satisfizer as propriedades:

1. Dois lados com a mesma extremidade não pertencem a uma mesma reta;

2. Nenhum par de lados se intersecta, exceto em seus vértices.

Definição 4 (Subconjunto do plano convexo). Um subconjunto do plano é dito convexo se o segmento ligando quaisquer dois de seus pontos está totalmente nele contido.

Notamos que, pela definição de polígono simples, todo ângulo do polígono é próprio ${ }^{1}$.

Teorema 1. A interseç̧ão de conjuntos convexos é um conjunto convexo.

Demonstração. Com efeito, seja $\bigcap_{\lambda \in L} A_{L}$ a intersecção de uma família de conjuntos convexos $\left(A_{\lambda}\right)_{\lambda \in L}$ com índices em $L$. Sejam $P$ e $Q$, pontos quaisquer dessa intersecção. Então $P$ e $Q$ pertencem a $A_{\lambda}$ para todo $\lambda \in L$. Logo, $P Q$ está inteiramente contido em cada um dos $A_{\lambda}$, pois cada um deles é convexo. Logo $P Q$ está inteiramente contido em $\bigcap_{\lambda \in L} A_{L}$ e o resultado está demonstrado.

Exemplo 1 (Convexidade ângulo). O interior do ângulo próprio $\angle A B C$ é uma região convexa do plano e o exterior é uma região não convexa.

Associamos ao interior do ângulo próprio $\angle A B C$ a medida padrão $\alpha$ de $\angle A B C$ e ao exterior de $\angle A B C$ a medida reflexa $360^{\circ}-\alpha$.

A partir de um ângulo próprio $\angle A B C$ podemos construir um quadrilátero, cujo interior está contido no exterior de $\angle A B C$, conforme Figura 2a. Nesse caso, o ângulo $\angle A B C$ interno ao quadrilátero $A B C D$ terá a medida reflexa de $\angle A B C$. Dizemos apenas, para simplificar a linguagem, que o ângulo $\angle A B C$, interno ao quadrilátero $A B C D$, é um ângulo reflexo. De uma forma geral, um ângulo interno de um polígono simples será dito reflexo ou côncavo, quando a medida angular associada ao referido ângulo for a reflexa. Intuitivamente, o interior do polígono está contido, ao menos localmente, no exterior do ângulo. Perceba esse último aspecto no vértice $O$ da Figura $2 \mathrm{~b}$. O ângulo do polígono será dito convexo quando a medida associada for a padrão e, novamente pela intuição, o interior do polígono, ao menos localmente, estará contido no interior do ângulo.

Exemplo 2. Um polígono convexo não poder ter um ângulo reflexo. Com efeito, o segmento ligando os vértices do ângulo reflexo não pode estar totalmente contido no interior do polígono (Figura 2).

O Teorema 1 permite que demonstremos a convexidade de várias figuras geométricas planas conhecidas. Dentre elas, teremos a possibilidade de demonstrar a convexidade do disco.

Teorema 2 (Convexidade do disco). O círculo limita uma figura convexa do plano.

\footnotetext{
${ }^{1}$ Com ângulo do polígono queremos dizer aqueles ângulos que obtemos estendendo dois lados adjacentes, obtendo dois raios a partir do ponto comum aos lados.
} 


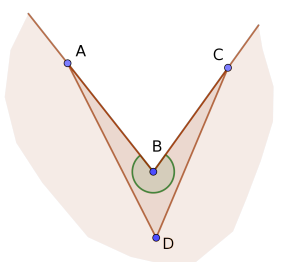

(a) Quadrilátero não convexo.

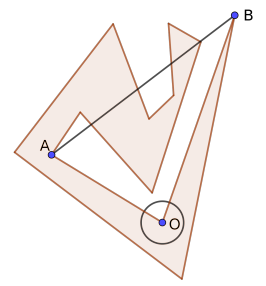

(b) ângulo reflexo em um polígono simples.

Figura 2: Polígonos com ângulos reflexos.

Demonstração. Primeiro esclarecemos que no nosso contexto o disco é a região limitada pelo seu círculo. Sejam $\Gamma(O, r)$ um círculo de centro $O$ e raio $r$ e $\mathcal{D}(O, r)$ o disco associado. Para cada $M \in \Gamma$, a reta tangente a $M$ define um semiplano $\mathcal{H}_{M}$ contendo o disco $\mathcal{D}$. Afirmamos que $\mathcal{D}=\bigcap_{M \in \Gamma} \mathcal{H}_{M}$. Primeiro notamos que da forma como fora definido, $\mathcal{D} \subset \mathcal{H}_{M}$ para todo $M$, portanto $\mathcal{D} \subset \bigcap_{M \in \Gamma} \mathcal{H}_{M}$. Agora, seja $N \in \bigcap_{M \in \Gamma} \mathcal{H}_{M}$ e supomos temporariamente que $N \notin \mathcal{D}$. Consideremos o segmento $O N$; da forma como definimos $N, \overline{O N}>r$. Pelos axiomas de medida, existe $P \in O N$, entre $O$ e $N$, tal que $\overline{O P}=r$, portanto $P \in \Gamma$ (Figura 3). A reta tangente a $\Gamma$ por $P$ deixa $N$ em um semiplano e $O$ em outro, de forma que $N \notin \bigcap_{M \in \Gamma} \mathcal{H}_{M}$, pois $\mathcal{D}$ está no mesmo semiplano de $O$ da reta tangente por $P$. Portanto, $N \in \mathcal{D}$.

Isso mostra que $\mathcal{D} \supset \bigcap_{M \in \Gamma} \mathcal{H}_{M}$ e a igualdade é verificada. Para finalizar, é só notar que $\bigcap_{M \in \Gamma} \mathcal{H}_{M}$ é uma intersecção infinita de conjuntos convexos e, pelo Teorema 1, é um conjunto convexo. Isso encerra a demonstração.

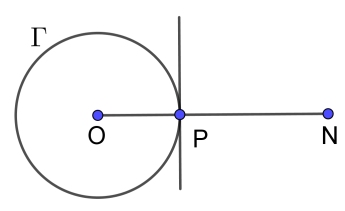

Figura 3: Semiplano determinado pela tangente ao círculo.

Definição 5 ( $1^{a}$. Definição de Polígono Convexo). Um polígono simples $\mathcal{P}$ é convexo se limita uma figura convexa plana ${ }^{2}$.

A Definição 5 é a mais utilizada na educação básica para definir polígono convexo ou a região que o mesmo limita. Uma breve busca na internet com a palavra-chave "polígono convexo" retorna, em sua maioria, por ela. Por exemplo, no site do Portal Escola ${ }^{3}$ obtém-se: "Um polígono é convexo

\footnotetext{
${ }^{2}$ Perceba que estamos assumindo implicitamente que um polígono simples admite um interior. Esse fato será demonstrado no Teorema 4.

${ }^{3}$ Brasil Escola. Disponível em <https://brasilescola.uol.com.br/matematica/poligonos-convexos.htm>. Acesso
} em: $27 / 03 / 2019$. 
quando todos os pontos de um segmento de reta que possui as extremidades no interior do polígono também estão dentro dele". Esta mesma definição pode ser encontrada em livros didáticos como no livro A conquista da matemática [8, p148] Outras definições alternativas são apresentadas para polígonos convexos usando retas de apoio (normalmente essa não é a nomenclatura usada no ensino básico) ou a noção de boca (essa também não é uma noção comum no ensino básico). Definiremos "reta de apoio" e "triângulo boca" mais adiante neste artigo. Uma consulta a livros didáticos indica que geralmente apresenta-se apenas uma definição de polígono convexo e não são abordadas outras equivalentes, já que uma é suficiente para caracterizá-lo. Além disso, após apresentada a definição, indica-se nos livros didáticos que dali em diante somente serão considerados os polígonos convexos.

Definição 6 (Reta de apoio). Diz-se que $r$ é uma reta de apoio do polígono $\mathcal{P}$ quando $\mathcal{P}$ tem pelo menos um ponto em comum com $r$ e quando $\mathcal{P}$ está contido inteiramente em um dos semiplanos fechados determinados por $r$.

Notamos que por um vértice de um polígono podemos obter uma quantidade infinita de retas de apoio (Figura 4a). Por um ponto interno de um lado, porém, a reta de apoio, caso exista, conterá todos os pontos do lado (Figura 4b). A Figura 4c mostra um caso em que $t$ não e uma reta de apoio do polígono.

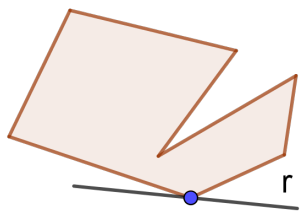

(a) Contendo apenas um vértice.

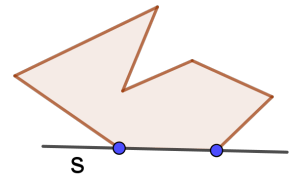

(b) Contendo um lado.

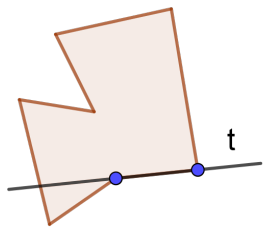

(c) Contraexemplo.

Figura 4: Retas de apoio: Exemplos e contraexemplos.

Teorema 3 (Caracterização da convexidade). Toda figura plana limitada por um polígono convexo é uma intersecção de um número finito de semiplanos.

Demonstração. Seja $\mathcal{P}: A_{1} A_{2} \ldots A_{n}$ um polígono convexo. Mostraremos que a figura $\Phi$, limitada por $\mathcal{P}$ é uma intersecção de um número finito de semiplanos. Para tal, mostraremos que toda reta que contém um dos lados de $\mathcal{P}$ é uma reta de apoio de $\mathcal{P}$. De fato, vamos supor, sem perda de generalidade, que a reta $\overleftrightarrow{A_{1} A_{2}}$, que contém o lado $A_{1} A_{2}$, não é uma reta de apoio de $\mathcal{P}$. Sejam $M$ um ponto entre $A_{1}$ e $A_{2}$ e $\mathcal{H}_{1}$ e $\mathcal{H}_{2}$ os semiplanos determinados pela reta $\overleftrightarrow{A_{1} A_{2}}$. Escolhemos um ponto $B$ pertencente a $\Phi$ em $\mathcal{H}_{1}$ e um ponto $C$ pertencente a $\Phi$ em $\mathcal{H}_{2}$ (Figura 5 ). Pela convexidade de $\Phi$ todos os pontos da figura limitada pelo triângulo $A_{1} M B$ pertencem a $\Phi$, analogamente todos os pontos da figura limitada pelo triângulo $A_{1} M C$ pertencem a $\Phi$. Logo, $A_{1} M$ está contido no interior de $\Phi$ e assim os pontos entre $A_{1}$ e $M$ não são pontos de fronteira de $\Phi$, o que é uma contradição, pois $A_{1} M \subset A_{1} A_{2}$ e $A_{1} A_{2}$ é um lado de $\mathcal{P}$. Quando dizemos que os pontos entre $A_{1}$ e $M$ são interiores a $\Phi$ vem do seguinte: $A_{1} M$ é uma diagonal interna do quadrilátero $A_{1} B M C$ e o interior de $A_{1} B M C$ é composto pelos interiores dos triângulos $A_{1} B M$ e $A_{1} C M$ e pelos pontos 
de $A_{1} M$, exceto por $A_{1}$ e $M$. Logo, qualquer círculo suficientemente pequeno centrado no ponto $P$, entre $A_{1}$ e $M$ encerrará pontos somente de $\Phi$. Dessa forma $\overleftrightarrow{A_{1}} A_{2}$ é uma reta de apoio de $\mathcal{P}$ e o mesmo resultado vale para todos os lados de $\mathcal{P}$. Portanto, a figura $\Phi$ está contida em cada um dos semiplanos que contém $\mathcal{P}$, cuja fronteira é uma reta de apoio de $\mathcal{P}$. A intersecção de todos os semiplanos é a figura $\Phi$. Isso era o queríamos demonstrar.

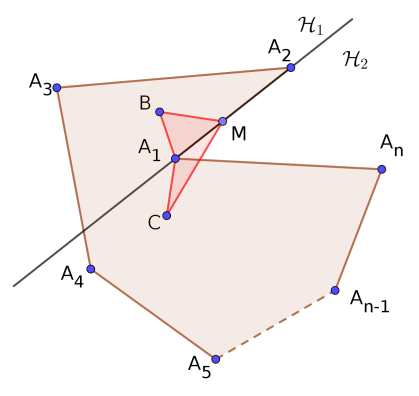

Figura 5: Ideia da demonstração do Teorema 3.

Reciprocamente, uma interseç̧ão de um número finito de semiplanos, se determinar uma figura limitada, essa figura terá um polígono simples como fronteira e será convexa, por ser uma intersecção de figuras convexas.

O Teorema 3 fornece-nos duas conclusões importantes. A primeira é uma nova caracterização de convexidade para polígonos simples expressa na Definição 7. A segunda conclusão é a determinação do interior do polígono simples convexo, conforme Definição 8.

Definição 7 ( $2^{a}$. Definição de Polígono Convexo). Um polígono $\mathcal{P}$ é convexo quando cada reta que contém um de seus lados é uma reta de apoio de $\mathcal{P}$.

Definição 8 (Interior do polígono convexo). Define-se interior do polígono simples convexo $\mathcal{P}$ a intersecção dos semiplanos abertos cuja fronteira é uma reta de apoio de $\mathcal{P}$ e que contém $\mathcal{P}$, exceto pelo lado em que se apoia. A região limitada por $\mathcal{P}$ é definida como a união dos pontos de $\mathcal{P}$ com os seus pontos interiores. Essa região será denotada por $\Phi$.

A Definição 7 também é usada para caracterizar polígonos convexos no ensino fundamental e médio. Exemplificando, o livro "Conexões com a matemática", cuja organizadora e editora responsável é Juliane Matsubara Barroso, traz a seguinte definição "Se a reta que passa por qualquer um dos vértices consecutivos mantiver todos os demais vértices no mesmo semiplano, então tal polígono será convexo. Caso contrário tem-se um polígono não convexo." [13, p118]. Observa-se que nessa definição não é feita alusão à reta de apoio, porém percebe-se que a reta citada é uma reta de apoio do polígono. Nesse mesmo livro o equivalente à nossa Definição 5 é apresentado como sendo uma propriedade de polígonos convexos: "As regiões convexas apresentam uma propriedade: todo segmento com extremidades pertencentes à região está contido nela." [13, p118]. Portanto, o livro apresenta uma definição e uma propriedade de polígono convexo, sem mencionar que ambas as caracterizações são equivalentes. Nesse artigo tentamos elucidar este ponto provando à equivalência das Definições 5 e 7 por meio do Teorema 3. O livro "Matemática: Paiva" de Manoel Paiva também 
utiliza a reta de apoio para definir polígono convexo: "Um polígono é convexo se, e somente se, a reta $r$ que contém qualquer um de seus lados deixa o polígono contido em um mesmo semiplano de origem." [16, p67]. Note que a reta $r$ mencionada é uma reta de apoio do polígono. Nesse livro não é descrita outra propriedade ou definição que caracterize polígonos convexos. Em ambos os livros, após definidos os polígonos convexos, apenas esses serão estudados.

Para os polígonos simples não convexos, as retas que contêm os lados não são necessariamente retas de apoio. Embora seja altamente intuitivo que um polígono simples $\mathcal{P}$ separe os pontos do plano que não pertencem a $\mathcal{P}$ em pontos internos e externos, essa propriedade precisa ser provada. Demonstraremos na sequência que, por mais complicado que seja $\mathcal{P}$, o seu complementar no plano é decomposto em duas regiões disjuntas, o interior limitado e o exterior ilimitado. Percebe-se que a visualização do interior de $\mathcal{P}$ nem sempre é imediata e pode, em alguns casos, tornar-se uma tarefa difícil. A que região do polígono $\mathcal{P}$ os pontos $A, B, C, D$ e $E$ da Figura 6 pertencem? Demonstraremos também uma forma de decidir se um ponto qualquer do plano, que não esteja em $\mathcal{P}$, está no interior ou no exterior de $\mathcal{P}$.

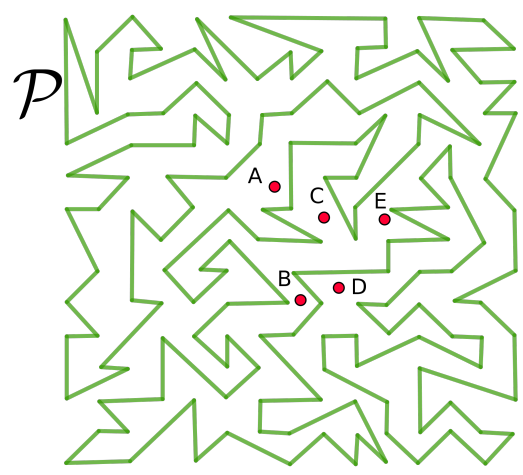

Figura 6: Interior do Polígono Simples. FONTE: Adaptado de [6, p282].

O Teorema 4 é válido para quaisquer curvas fechadas simples no plano. Essa versão generalizada é conhecida como o Teorema da Curva de Jordan, em homenagem ao matemático francês Camile Jordan (1838-1922). Esse resultado é um daqueles teoremas intuitivos e fáceis de enunciar, cuja demonstração é altamente não trivial. Para nosso alívio a versão que nos interessa (Teorema 4), em que a curva fechada simples é um polígono simples, não oferece as dificuldades do caso geral.

Teorema 4 (Teorema da Curva de Jordan Poligonal). Qualquer polígono simples $\mathcal{P}$ divide o plano $\Pi$ em duas classes disjuntas de pontos, não situadas em $\mathcal{P}$, dos quais $\mathcal{P}$ é a fronteira comum. As duas classes de $\Pi$ são o interior de $\mathcal{P}$, que é limitado e o exterior ilimitado. Qualquer poligonal ligando um ponto do interior a um ponto do exterior de $\mathcal{P}$, corta $\mathcal{P}$ em pelo menos um ponto. Dois pontos quaisquer da mesma classe podem ser unidos por uma poligonal que não corta $\mathcal{P}$, contida na mesma classe ${ }^{4}$.

\footnotetext{
${ }^{4} \mathrm{~A}$ propriedade de ligação dos pontos da classe por uma poligonal contida na respectiva classe é chamada de conexidade por caminhos. Quando ambos interior e exterior são conexos por caminhos, diz-se que o interior é simplesmente conexo, isto é, não contém furos e nem ilhas (partes isoladas da figura). Para uma maior compreensão desses aspectos leia [2] e as referências lá sugeridas.
} 
A demonstração que por ora se apresenta do Teorema 4 é uma versão ampliada da que foi apresentada em [6, p306].

Demonstração. Seja uma reta $r$ no plano não paralela a qualquer dos lados de $\mathcal{P}$. Desde que $\mathcal{P}$ tem uma quantidade finita de lados, isso é sempre possível. Definimos duas classes $\mathcal{A}$ e $\mathcal{B}$ de pontos do plano tais que:

- Um ponto $A \in \mathcal{A}$ se um raio com ponto inicial em $A$, paralelo a $r$, corta $\mathcal{P}$ um número par de vezes;

- Um ponto $B \in \mathcal{B}$ se um raio com ponto inicial em $B$, paralelo a $r$, corta $\mathcal{P}$ um número ímpar de vezes;

Dois pontos têm a mesma paridade quando pertencem à mesma classe.

Quando o raio passa pelos vértices temos duas situações especiais a considerar:

1. Quando os lados do polígono no vértice que o raio passa estão do mesmo lado do raio, não contamos essa situação como um corte (veja os vértices $R_{i}$ na Figura 7a);

2. Quando os lados do polígono no vértice que o raio passa estão em lados opostos do raio, contamos essa situação como um corte (veja os vértices $S_{j}$ na Figura $7 \mathrm{~b}$ ).

Mostraremos inicialmente que todos os pontos de um segmento de reta que não corta $\mathcal{P}$ têm a mesma paridade. Imagine o ponto $P$ deslocando-se de $M$ para $N$ no segmento $M N$. Conforme o ponto $P$ move-se no segmento $M N$, os raios que emanam de $P$ na direção escolhida vão varrendo dois conjuntos contidos em uma faixa no plano nos dois semiplanos determinados pela reta $M N$. Como o segmento $M N$ não corta $\mathcal{P}$, a quantidade de cortes somente pode mudar quando um raio passar por um vértice. Então vamos analisar essa passagem pelos vértices com cuidado.

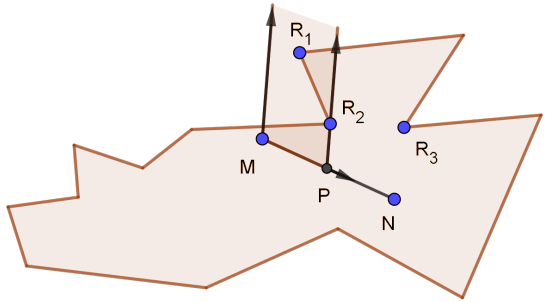

(a) Segmento interno.

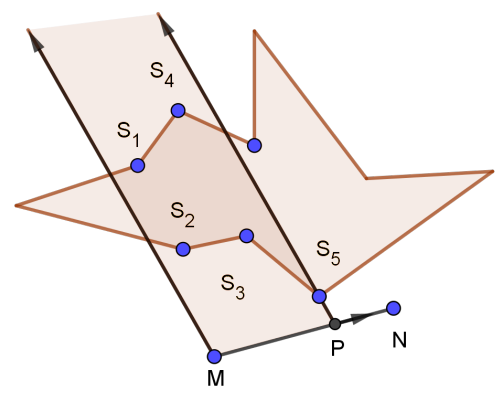

(b) Segmento externo.

Figura 7: Varredura de vértices.

Quando um raio passa por um vértice do tipo 1, logo após a varredura passar pelo vértice, a quantidade de cortes aumenta ou diminui em dois. Na Figura 7a nos vértices $R_{1}$ e $R_{3}$ acrescentamse dois cortes e no vértice $R_{2}$ a quantidade de cortes diminui dois. Quando um raio passa por um 
vértice do tipo 2 a quantidade de cortes não é alterada (são os vértices $S_{i}$ da Figura $7 \mathrm{~b}$ ). Isso mostra que a paridade não muda quando a varredura passa pelos vértices. Portanto, se o ponto $M \in \mathcal{A}$ (respectivamente $\mathcal{B}$ ), então todos os pontos do segmento também pertencerão a $\mathcal{A}$ (respectivamente $\mathcal{B})$. Como consequência do que fora demonstrado, qualquer poligonal ligando um ponto $A \in \mathcal{A}$ a um ponto $B \in \mathcal{B}$ deve cortar $\mathcal{P}$. Porque se assim não fosse a paridade de todos os pontos do caminho e, em particular, de $A$ e $B$ seriam a mesma.

Mostraremos agora que dois pontos quaisquer da mesma classe podem ser unidos por um caminho poligonal que não corta $\mathcal{P}$. Sejam $A$ e $B$ os dois pontos. Se o segmento $A B$ não corta $\mathcal{P}$, esse segmento é o caminho que queríamos. De outro modo, sejam $A^{\prime}$ e $B^{\prime}$ o primeiro e o último ponto de intersecção de $A B$ com $\mathcal{P}$, respectivamente. Construímos o caminho começando em $A$ ao longo do segmento $A A^{\prime}$, em seguida, desviando um pouco antes de $A^{\prime}$ e seguindo bem próximo ao longo de $\mathcal{P}$ até que $\mathcal{P}$ retorne a $A B$ em $B^{\prime}$. Dessa forma, a poligonal volta ao segmento $A B$ e está bem próxima de $B^{\prime}$, conforme Figura 8.

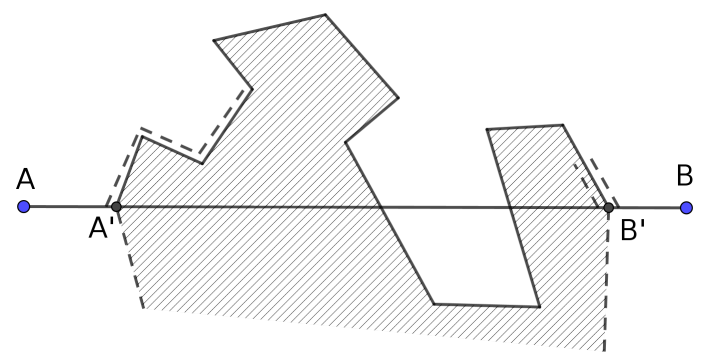

Figura 8: Conexidade.

A poligonal obtida volta a $A B$ entre $B^{\prime}$ e $B$. Com efeito, percebemos que para dois pontos $R$ e $R^{\prime}$ suficientemente próximos um do outro, mas em lados opostos de algum lado de $\mathcal{P}$ têm paridade diferente, porque o raio partindo de $R$ cortará $\mathcal{P}$ em um ponto a mais do que o raio passando por $R^{\prime}$ (Figura 9).

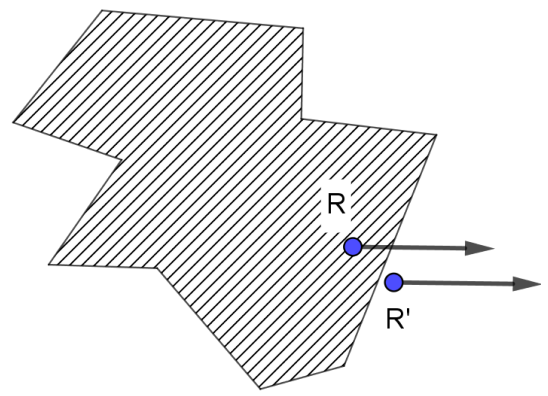

Figura 9: Paridade de pontos próximos a um lado do polígono. 


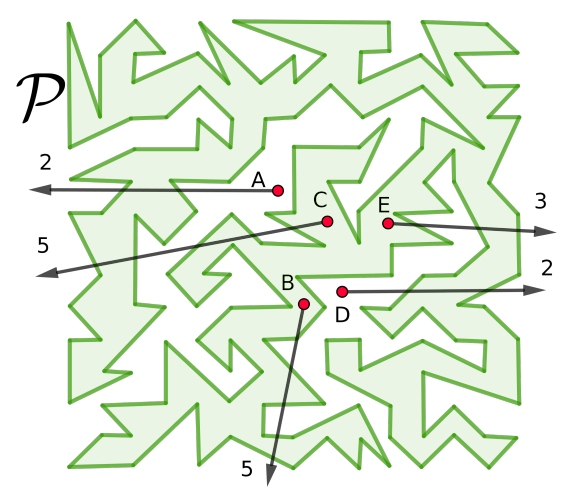

Figura 10: Identificando pontos internos e externos ao polígono $\mathcal{P}$ da Figura 6.

Como a poligonal construída volta ao segmento $A B$ em algum ponto muito próximo de $B^{\prime}$ sem cortar o polígono $\mathcal{P}$, para que a paridade seja mantida ela deverá voltar ao segmento $A B$ entre os pontos $B^{\prime}$ e $B$. Isso conclui a demonstração do teorema.

Identificamos a classe $\mathcal{A}$ como o exterior de $\mathcal{P}$, uma vez que, se percorrermos uma distância suficiente ao longo de qualquer raio na direção fixada chegaremos em um ponto $C$, do qual além dele não haverá nenhuma interseç̧ão com $\mathcal{P}$, de modo que todos os pontos além de $C$ tem paridade zero. O interior de $\mathcal{P}$ é a classe $\mathcal{B}$. Também denotaremos por $\Phi$, tal como fizemos para os polígonos convexos, o conjunto formado pela união dos pontos internos de $\mathcal{P}$ com os pontos de $\mathcal{P}$. Usando os resultados do Teorema 4 podemos analisar os pontos da Figura 6 e decidir a quais regiões os pontos $A, B, C, D$ e $E$ pertencem (Figura 10).

Vemos que $A$ e $D$ têm paridade par (dois cortes); $E$ tem paridade impar (três cortes); $B$ e $C$ têm paridade impar (cinco cortes). Portanto, $A$ e $D$ são pontos externos e $B, C$ e $E$ são internos a $\mathcal{P}$. Perceba que se tivéssemos escolhido outras semirretas, o número de cortes poderia aumentar ou diminuir, mas conforme demonstramos no Teorema 4 a paridade não mudaria.

Os Teoremas 5, 6 e 7 são versões reinterpretadas apenas para polígonos, daquelas apresentadas em [20] para figuras planas quaisquer limitadas por curvas fechada simples.

Teorema 5. Toda reta passando por um ponto interior de um polígono convexo $\mathcal{P}$, corta $\mathcal{P}$ em dois pontos.

Demonstração. Sejam $\Phi$ a região limitada por $\mathcal{P}, P$ um ponto pertencente ao interior de $\mathcal{P}$ e $r$ uma reta qualquer que passa pelo ponto $P$. A reta $r$ e $\Phi$ são conjuntos convexos; portanto sua intersecção também é um conjunto convexo (Teorema 1). As possibilidades para $r \bigcap \Phi$ ser um conjunto convexo são: toda a reta, uma semirreta, um segmento, ou um ponto. Dado que $\Phi$ é uma figura convexa limitada e $r \bigcap \Phi$ é mais do que um ponto, pois $P$ é um ponto interno de $\mathcal{P}$, resta apenas uma possibilidade: $r \bigcap \Phi$ é um segmento. As extremidades $A$ e $B$, pertencentes a $\Phi$ não podem ser pontos internos, logo, são pontos de fronteira, isto é, pertencem a $\mathcal{P}$ (Figura 11). 


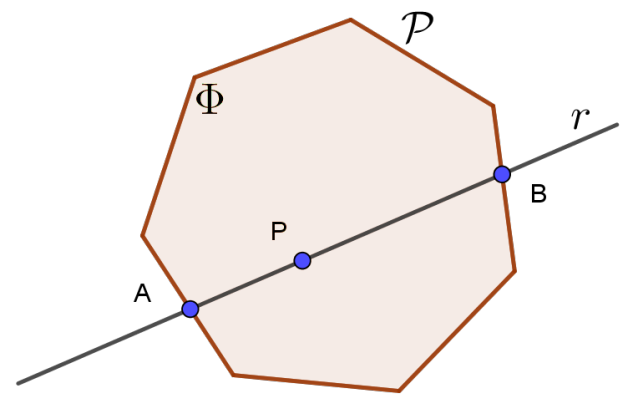

Figura 11: Reta por um ponto interior ao polígono convexo $\mathcal{P}$.

Teorema 6. Se toda reta passando por um ponto interior de um polígono simples $\mathcal{P}$, cortar $\mathcal{P}$ em dois pontos, então $\mathcal{P}$ limita uma figura convexa.

Demonstração. O Teorema 6 é equivalente à sua versão contrapositiva:

Para toda figura $\Phi$, limitada por um polígono simples não convexo $\mathcal{P}$, existe uma reta que corta $\mathcal{P}$ em mais do que dois pontos.

Faremos uma demonstração direta da formulação contrapositiva do teorema. Dado que $\Phi$ não é uma figura convexa, pode-se encontrar dois pontos $A$ e $B$ de $\Phi$, tal que o segmento $A B$ não esteja inteiramente contido em $\Phi$. Seja $C$ um ponto do segmento $A B$ não pertencente a $\Phi$ (Figura 12a).

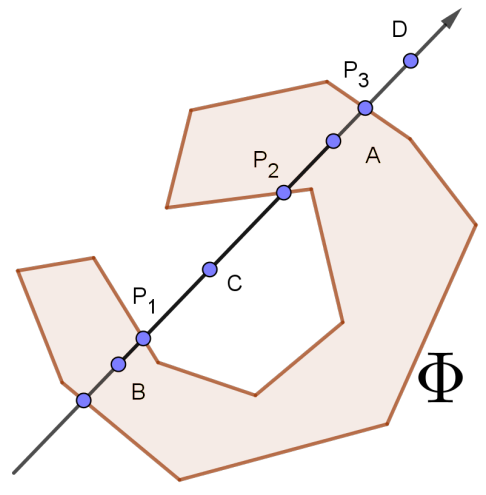

(a)

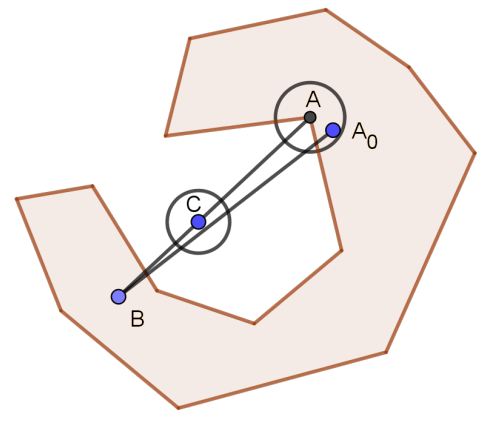

(b)

Figura 12: Ponto $C$ externo a $\Phi$ e ao segmento $A B$

Podemos sempre assumir que $A$ é um ponto do interior de $\mathcal{P}$. De fato, se $A \in \mathcal{P}$, poderíamos encontrar um ponto $A_{0}$ interior a $\mathcal{P}$, suficientemente próximo de $A$, tal que $A_{0} B$ também contivesse 
pontos exteriores a $\Phi$ (Figura 12b). Assim sendo, assumimos que $A$ seja um ponto interior a $\mathcal{P}$, conforme Figura 12a. Pelo Teorema 4, no segmento $B C$ há um ponto $P_{1} \in \mathcal{P}$ (que pode coincidir com $B$ ), já que $B \in \Phi$ e $C \notin \Phi$. No segmento $A C$ há, da mesma forma, um ponto $P_{2} \in \mathcal{P}$ pois $A \in \Phi$ e $C \notin \Phi$. Finalmente, se prolongarmos o segmento $A B$ além de $A$, obtemos uma semirreta $A D$ que emana do ponto $A$ do interior de $\mathcal{P}$. Nessa semirreta há também, pelo menos um ponto $P_{3} \in \mathcal{P}$ pois $\Phi$ é uma figura limitada e satisfaz as condições do Teorema 4. Então, na reta $A B$ existem pelo menos os três pontos de fronteira $P_{1}, P_{2}$ e $P_{3}$ de $\Phi$. Isso era o que desejávamos demonstrar.

Dos Teoremas 5 e 6 , podemos formular uma nova definição de convexidade para polígonos simples:

Definição 9 ( $3^{a .}$ Definição de Polígono Convexo). Um polígono simples é convexo quando toda reta que passa por um ponto interior de $\mathcal{P}$, $\operatorname{cortar} \mathcal{P}$ em apenas dois pontos.

Seguimos nossa discussão por meio do Teorema 7, que formula a convexidade em termos das retas de apoio.

Teorema 7. Se através de cada ponto de um polígono simples $\mathcal{P}$ passar pelo menos uma reta de apoio, então $\mathcal{P}$ limita uma figura convexa.

Demonstração. Tal como fora feito no Teorema 6, demonstraremos a versão contrapositiva do Teorema 7. Mostraremos que todo polígono não convexo tem um ponto no qual não pode passar uma reta de apoio. Sejam $\Phi$ a figura limitada pelo polígono não convexo $\mathcal{P}$ e dois pontos $A$ e $B$ pertencentes a $\Phi$, tal que $A B$ não esteja inteiramente contido em $\Phi$. Isso quer dizer que existe um ponto $C$, entre $A$ e $B$, tal que $C \notin \Phi$ (Figura 12). Assim como justificamos na demonstração do Teorema 6, podemos sempre assumir que $A$ seja um ponto interior a $\mathcal{P}$. Usando os mesmos passos da demonstração do Teorema 6, obtemos a Figura 12a. Demonstraremos que o ponto $P_{2}$ daquela construção é um ponto de $P$ que não pode passar uma reta de apoio. Com efeito, a reta $A B$ por $P_{2}$ não é uma reta de apoio, pois passa pelo ponto interior $A$. Nenhuma outra reta $r$ por $P_{2}$ é uma reta de apoio, uma vez que os pontos $A$ e $B$ de $\Phi$ estariam em diferentes lados de $r$. Isso encerra a demonstração.

O Teorema 7 pode ser generalizado para figuras planas quaisquer ${ }^{5}$.Sua demonstração pode ser consultada em [2, p126].

Definição 10 (4 ${ }^{a}$. Definição de Polígono Convexo). Um polígono simples $\mathcal{P}$ é convexo quando através de cada ponto de $\mathcal{P}$ passar pelo menos uma reta de apoio.

Poderíamos usar o caso generalizado do Teorema 7 para demonstrar o Teorema 2. Concluiríamos que o círculo limita uma curva convexa, porque por cada ponto do círculo existe uma (e somente uma) reta de apoio: a reta tangente no ponto em questão. Para os polígonos convexos, nos vértices existe uma infinidade de retas de apoio e nos outros pontos do polígono somente uma.

\footnotetext{
${ }^{5}$ Figuras planas no contexto de nossa discussão são subconjuntos do plano limitados por uma curva fechada simples. Para maiores detalhes o leitor pode consultar [2, p41].
} 


\section{Fecho convexo e polígonos simples}

Dado um subconjunto $\mathcal{A}$ de pontos do plano, em diversas situações da matemática interessa saber determinar a menor figura convexa que contém $\mathcal{A}$. Essa figura abarcante é chamada de fecho convexo de $\mathcal{A}$. Se $\mathcal{A}$ for um conjunto discreto de pontos ou uma figura $\Phi$ limitada por um polígono simples $\mathcal{P}$, o fecho será uma figura convexa limitada por um polígono. Estudaremos o fecho quando $\mathcal{A}=\Phi$, isto é, quando $\mathcal{A}$ for uma figura $\Phi$ limitada por um polígono simples $\mathcal{P}$.

Começamos essa seção com a demonstração de um lema que nos será útil nas demonstrações subsequentes.

Lema 1. Todo polígono simples com mais de três lados tem pelo menos uma diagonal interna ${ }^{6}$.

Demonstração. Seja $V$ o vértice verticalmente mais abaixo dentre todos os outros vértices do polígono simples $\mathcal{P}$. Caso haja mais do que um, considere aquele que está mais à direita. Sejam $A$ e $B$ seus vértices vizinhos. Se $A B$ for uma diagonal interna, terminamos aqui a demonstração. Supondo que $A B$ não seja uma diagonal interna. Dado que $n>3$, o triângulo $A V B$ contém pelo menos um vértice de $\mathcal{P}$ diferente de $A, V$ e $B$. Seja $Q$ o vértice de $\mathcal{P}$ mais próximo de $V$, em que a distância é medida ortogonalmente à reta $A B$. A reta $r$ paralela à reta $A B$ por $Q$ determina um triângulo formado somente por pontos de $\Phi$ (Figura 13). O segmento $V Q$ é uma diagonal interna do polígono $\mathcal{P}$ e o teorema está demonstrado.

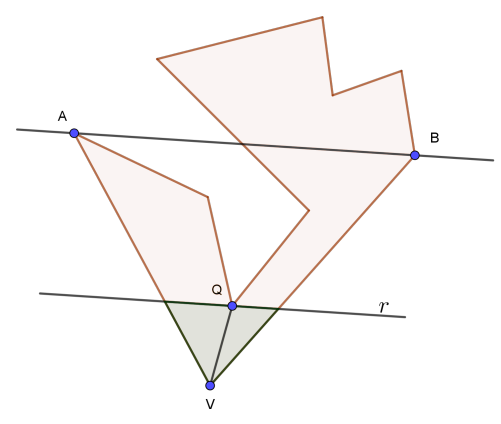

Figura 13: Diagonal interna do polígono $\mathcal{P}$.

Teorema 8. Todo polígono simples com mais de três lados pode ser triangularizado em $n-2$ triângulos. O número de diagonais da decomposição é $n-3$.

No presente artigo omitiremos a demonstração do Teorema 8. A demonstração desse Teorema é feita por indução e usa o Lema 1. Para os detalhes veja [2, p70].

O Teorema 8 será usado na demonstração dos resultados subsequentes. Sua demonstração no ensino fundamental e médio, quando é apresentada, geralmente é para o caso convexo, usando um

\footnotetext{
${ }^{6}$ Diagonal de um polígono é qualquer segmento que une dois vértices não consecutivos. A diagonal é interna quando está totalmente contida na região limitada pelo polígono. O conceito de diagonal não tem relação com o fato de o polígono ser convexo ou não.
} 
argumento combinatório simples que aproveita o fato de todas as diagonais do polígono convexo serem internas. A triangularização ainda pode ser estendida para polígonos contendo furos ou ainda para quaisquer figuras conexas com fronteira formada por segmentos de retas. Para a geometria discreta e computacional, os algoritmos usados para implementação de rotinas computacionais, a triangularização funciona como a fatoração de um número inteiro em primos, porém sem a unicidade na decomposição do caso aritmético proveniente do Teorema Fundamental da Aritmética [15, p1]. Este teorema tem sua utilidade no cálculo de áreas, centro de massa etc, ele destaca que todo polígono simples pode ser triangularizado reduzindo o cálculo de áreas de um polígono ao cálculo de áreas de triângulos. Esse resultado pode ser utilizado na educação básica para o cálculo da área de polígonos simples não regulares, mas o que geralmente se observa nos livros didáticos é que o cálculo de áreas de uma figura qualquer é feito por meio de uma malha quadriculada onde a área da figura é aproximada pelas soma das área dos quadrados da malha que estão no interior da figura.

Para o que segue precisamos caracterizar corretamente os tipos de reentrância e saliência nos polígonos simples. Faremos isso nas definições que seguirão. As Definições 11, 12 e 13 são as comumente apresentadas em [14], [15] e no restante das publicações dos autores. As Definições 14 e 15 são apresentadas em $[12, \mathrm{p} 5]$.

Definição 11 (Vértice e diagonal principal). Diz-se que um vértice $A_{i}$ de um polígono simples $\mathcal{P}$ é um vértice principal quando a diagonal $A_{i-1} A_{i+1}$ intersecta $\mathcal{P}$ somente em seus extremos. A diagonal em questão é chamada de diagonal principal (Figura 14a).

Definição 12 (Ponta e triângulo orelha). O vértice principal $B_{j}$ do polígono simples $\mathcal{P}$ é chamado de ponta ${ }^{7}$ quando a diagonal $B_{j-1} B_{j+1}$ está inteiramente contida na figura limitada por $\mathcal{P}$. O triângulo $B_{j-1} B_{j} B_{j+1}$, contido na região limitada por $\mathcal{P}$, é chamado de triângulo orelha do polígono $\mathcal{P}$ (Figura 14b).

Definição 13 (Triângulo boca). O vértice principal $C_{i}$ do polígono simples $\mathcal{P}$ forma uma boca, quando a diagonal $C_{i-1} C_{i+1}$, exceto pelos seus pontos extremos, está inteiramente contida no exterior de $\mathcal{P}$. O triângulo $C_{i-1} C_{i} C_{i+1}$ é a referida boca (Figura 14b).

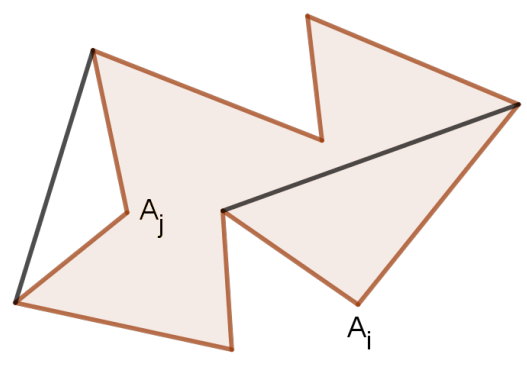

(a) Diagonal Principal.

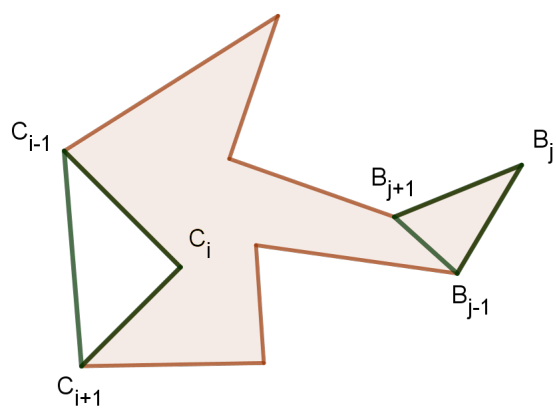

(b) Triângulos orelha e boca.

Figura 14: Diagonal principal, triângulos orelha e boca.

\footnotetext{
${ }^{7}$ ou ponta da orelha, do inglês "tip ear".
} 


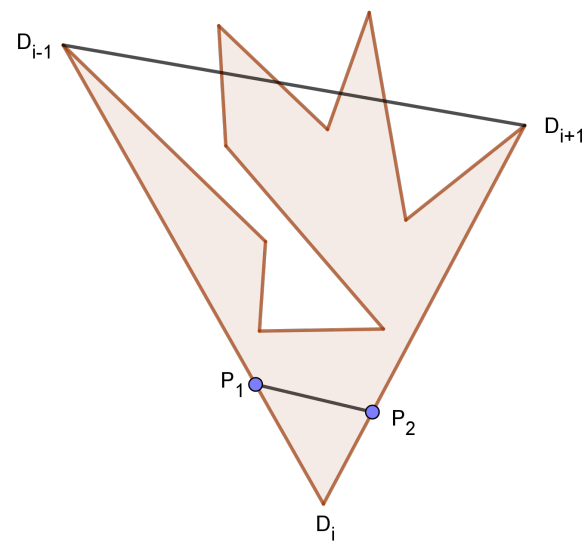

(a) Vértice saliente.

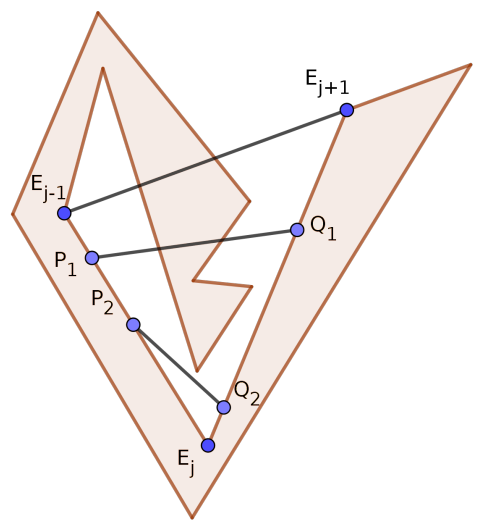

(b) Vértice reentrante.

Figura 15: Vértices salientes e reentrantes.

Além desses, existem os vértices que apresentam saliências e reentrâncias mais comuns. Apresentaremos na sequência as definições gerais por uma questão de completitude. As definições 12 e 13 são casos particulares das 14 e 15 .

Definição 14 (Vértice saliente). Um vértice $D_{i}$ de um polígono simples $\mathcal{P}$ diz-se um vértice saliente quando é possível escolher um ponto $P_{1}$ no interior do segmento $D_{i-1} D_{i}$ e outro ponto $P_{2}$ no interior do segmento $D_{i} D_{i+1}$ de modo que o segmento $P_{1} P_{2}$ esteja contido na figura limitada por $\mathcal{P}$ (Figura 15a).

Definição 15 (Vértice reentrante). Um vértice $E_{j}$ de um polígono simples $\mathcal{P}$ que não é saliente é dito ser um vértice reentrante. Isso significa que para qualquer ponto $P$ no interior de $E_{j-1} E_{j}$ e qualquer ponto $Q$ no interior de $E_{j} E_{j+1}$, o segmento $P Q$ não está inteiramente contido na figura limitada por $\mathcal{P}$ (Figura 15b).

O Teorema seguinte formaliza uma visão bastante intuitiva do polígono simples.

Teorema 9 (Teorema das duas orelhas). Todo polígono simples tem pelo menos duas orelhas disjuntas.

Demonstração. Dado um polígono $\mathcal{P}$ de $n$ lados, pelo Teorema 8 existe uma triangularização de $\mathcal{P}$ com $n-2$ triângulos. Cada um dos $n$ lados de $\mathcal{P}$ pertence a um desstes triângulos. Usando o Princípio das casas dos pombos interpretando os triângulos "como casas" e os lados "como pombos" há dois triângulos com dois lados de $\mathcal{P}$ cada um. O terceiro lado é, por sua vez, uma diagonal interna. Pela Definição 12, cada um dos triângulos (disjuntos) da triangularização é uma orelha. Os vértices comuns aos lados de $\mathcal{P}$ de cada uma das orelhas são, cada um, uma ponta distinta de $\mathcal{P}$.

Para o que segue continuaremos usando a mesma notação: $\mathcal{P}$ para um polígono simples e $\Phi$ para região limitada por $\mathcal{P}$ (a intersecção de $\mathcal{P}$ com o seu interior). 
Definição 16 (Fecho convexo. $1^{a .}$ Definição). Define-se fecho convexo de $\Phi$, e denota-se por $\operatorname{Conv}(\Phi)$, a intersecção de todos os conjuntos convexos que contêm $\Phi$. Em outras palavras, se $\Omega$ é convexo e $\Omega \supset \Phi$, então $\Omega \supset \operatorname{Conv}(\Phi)$.

Notamos que $\operatorname{Conv}(\Phi)$ está, portanto, contido em qualquer outro conjunto convexo que contém $\Phi$. Em uma linguagem menos precisa, podemos dizer que $\operatorname{Conv}(\Phi)$ é o menor conjunto convexo que contém $\Phi$.

Os Teoremas 10 e 11 são reinterpretações, para o contexto desse artigo, de exercícios sugeridos nas referências: [4] e [15]

Teorema 10. O polígono simples $\mathcal{P}^{\prime}$ com região limitada $\Phi^{\prime}$, que contém $\Phi$ (e contém $\mathcal{P}$ ) em seu interior, e que tem menor perímetro dentre todos os polígonos que contêm $\Phi$, é convexo.

Demonstração. Supondo que $\mathcal{P}^{\prime}: P_{1} \cdots P_{n}$ não seja convexo. Então existem dois pontos $A$ e $B$ pertencentes a $\Phi^{\prime}$ tal que $A B$ não esteja inteiramente contido em $\Phi^{\prime}$. Pelo Teorema da curva de Jordan Poligonal, o número de intersecções que o segmento $A B$ tem com $\mathcal{P}^{\prime}$ é par. Escolhemos os dois pontos $C$ e $D$ mais próximos de $B$. O interior do segmento $C D$ está totalmente contido no exterior de $\mathcal{P}^{\prime}$ (Figura 16).

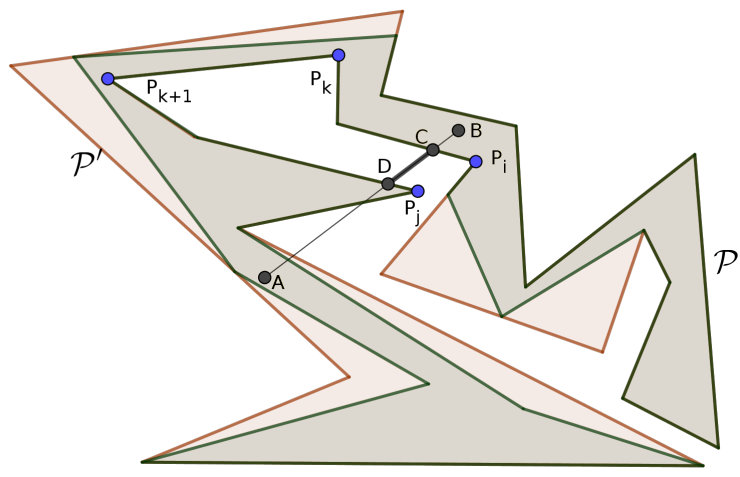

Figura 16: Visualização da ideia da demonstração do Teorema 10.

Naturalmente, $C$ e $D$ devem ser pontos de $\mathcal{P}^{\prime}$. Substituindo a poligonal $C \cdots P_{k} P_{k+1} \cdots D$ pelo segmento $C D$ obtemos o polígono $\mathcal{P}^{\prime \prime}: P_{1} \cdots P_{i} C D P_{j} \cdots P_{n}$, que contém ainda todos os pontos de $\Phi$ e tem perímetro menor do que $\mathcal{P}^{\prime 8}$, contrariando a hipótese sobre $\mathcal{P}^{\prime}$. Portanto, $\mathcal{P}^{\prime}$ é convexo.

Na sequência iremos demonstrar que a região limitada por $\mathcal{P}^{\prime}$ é o fecho convexo de $\Phi$, isto é, que $\Phi^{\prime}=\operatorname{Conv}(\Phi)$. Para tal precisamos demonstrar o Teorema que segue. Usaremos as mesmas notações do Teorema 10.

\footnotetext{
${ }^{8} \mathrm{O}$ comprimento da poligonal construída sobre o segmento $C D$ é maior do que o comprimento do segmento $C D$. Essa é uma consequência da Desigualdade Triangular. O leitor encontrará uma demonstração para esse resultado em [17, p41].
} 


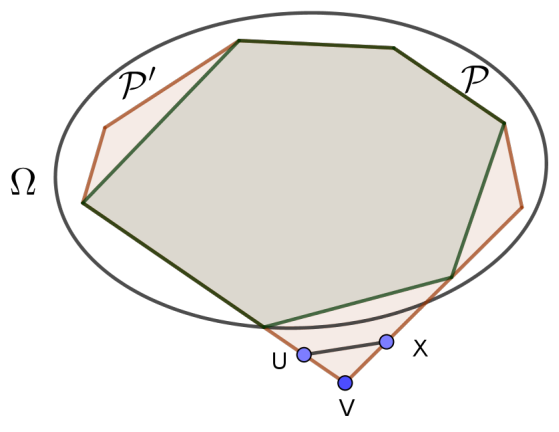

Figura 17: Visualização da ideia da demonstração do Teorema 11.

Teorema 11. Qualquer conjunto convexo $\Omega$ que contém $\Phi$, contém $\Phi^{\prime}$. Em outras palavras: Se $\Omega \supset \Phi$, então $\Omega \supset \Phi^{\prime}$ e $\Phi^{\prime}=\operatorname{Conv}(\Phi)$.

Demonstração. Demonstraremos essa proposição por redução ao absurdo. Assumamos que $\Omega \supset \Phi$ e que $\Omega \not \supset \Phi^{\prime}$. Nessas condições há um vértice $V$ de $\mathcal{P}^{\prime}$ que não pertence a $\Phi$ (Figura 17). Pois, se assim não fosse, todos os vértices de $\mathcal{P}^{\prime}$ estariam em $\Omega$ e da convexidade de $\Omega$, cada lado de $\mathcal{P}^{\prime}$ estaria contido em $\Omega$ e daí teríamos $\Omega \supset \Phi^{\prime}$. O vértice $V$ não pertence a $\Phi$, pois $\Omega$ contém todos os pontos de $\Phi$. Tomemos os pontos $U$ e $X$ nos lados que partem de $V$ em $\mathcal{P}^{\prime}$, suficientemente próximos a $V$ tal que o triângulo $U V X$ não contenha nenhum ponto de $\Phi$.

Substituindo $U X$ por $U V+V X$, obtemos um novo polígono $\mathcal{P}^{\prime \prime}$ contendo $\Phi$ e com perímetro menor do que $\mathcal{P}^{\prime}$. Essa contradição encerra a demonstração por redução ao absurdo e $\Omega \supset \Phi^{\prime}$, como queríamos.

Pela definição 16, podemos concluir da demonstração do Teorema 11 que $\Phi^{\prime}=\operatorname{Conv}(\Phi)$.

A figura geométrica plana formada por todas as retas de apoio de um polígono simples não convexo forma uma outra figura que chamaremos na sequência de $\Sigma$. Iniciamos a discussão com uma definição. O que discutiremos na sequência até a Definição 18, pode ser consultado em [20].

Definição 17. Dado um polígono simples $\mathcal{P}$, define-se $\Sigma$ o conjunto formado pelos semiplanos que contêm $\mathcal{P}$, determinados pelas retas suportes de $\mathcal{P}$.

Por ser uma intersecção de semiplanos, o Teorema 1 garante que $\Sigma$ é uma figura convexa. Mostraremos no Teorema 12 que $\Sigma$ é o fecho convexo de $\Phi$.

Teorema 12. A figura $\Sigma$ é a menor figura convexa que contém $\Phi$ (no sentido da Definição 16). Portanto, $\Sigma=\operatorname{Conv}(\Phi)$.

Demonstração. A figura $\Sigma$ é convexa por ser uma intersecção de semiplanos. A fronteira de $\Sigma$ é um polígono convexo $\mathcal{P}^{\prime \prime}$. Supondo que $\Sigma$ seja diferente de $\operatorname{Conv}(\Phi)$. Seja $\mathcal{P}^{\prime}$ o polígono que contém $\mathcal{P}$ com menor perímetro. Pelos Teoremas 10 e 11, a região $\Phi^{\prime}$ limitada por $\mathcal{P}^{\prime}$ é tal que $\Phi^{\prime}=\operatorname{Conv}(\Phi)$; portanto, $\Sigma \supset \operatorname{Conv}(\Phi)$. Dado que supomos provisoriamente que $\Sigma$ é diferente 
de $\operatorname{Conv}(\Phi)$, existe pelo menos uma reta de apoio de $\mathcal{P}^{\prime}$ (que limita $\operatorname{Conv}(\Phi)$ ) que não é reta de apoio de $\mathcal{P}^{\prime \prime}$. A última conclusão contraria a definição de $\Sigma$. $\operatorname{Logo}, \Sigma=\operatorname{Conv}(\Phi)$, como queríamos demonstrar.

Por causa do Teorema 12, podemos dar uma nova caracterização do fecho convexo da região $\Phi$ limitada por um polígono simples qualquer.

Definição 18 (Fecho convexo. $2^{a}$. Definição). Define-se fecho convexo de $\Phi$ o conjunto obtido pela intersecção de todos os semiplanos que contêm $\mathcal{P}$, determinados pelas retas de apoio de $\mathcal{P}$.

Uma visualização do fecho convexo da figura $\Phi$, limitada por $\mathcal{P}$, pode ser obtida com o seguinte experimento: Imaginamos o polígono sobre uma superfície plana na qual colocamos tachinhas sobre os vértices. Envolvemos $\Phi$ com um elástico de látex fino (Figura 18). Ele ficará esticado em algumas tachinhas, minimizando a distância entre elas: por isso formam segmentos. Apoiam-se em alguns dos vértices, pois são retas de apoio do polígono $\mathcal{P}$. A região limitada pelo elástico é o fecho convexo de $\Phi$.

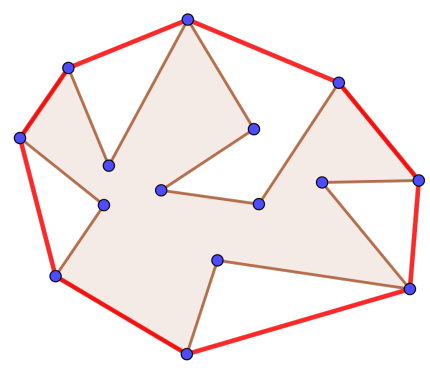

Figura 18: Fecho convexo da região limitada por um polígono simples.

O Teorema 13 tem bastante importância para a Geometria Computacional. Foi enunciado e demonstrado por Godfried T. Toussaint em 1991. Sua demonstração pode ser lida em [19].

Teorema 13 (Teorema da Boca). Exceto para polígonos convexos, todo polígono simples tem pelo menos uma boca.

Demonstração. Sejam $\mathcal{P}$ o polígono simples e $\Phi$ sua região limitada. Pelo Teorema 11, o polígono $\mathcal{P}^{\prime}$ limita o fecho convexo $\operatorname{Conv}(\Phi)$. Sendo que $\mathcal{P}$ não é convexo, existem lados de $\mathcal{P}^{\prime}$ que não são lados de $\mathcal{P}$. Pode acontecer duas situações:

1. O lado $A_{l} A_{l+2}$ de $\mathcal{P}^{\prime}$ que não está em $\mathcal{P}$ cobre uma boca de $\mathcal{P}$ e o teorema está demonstrado.

2. O lado $A_{j} A_{i}$ de $\mathcal{P}^{\prime}$ que não pertence a $\mathcal{P}$ cobre um "bolso" que se fecha nesse lado de $\mathcal{P}^{\prime}$. Esse bolso é outro polígono que se fecha em $A_{i} A_{j}$. Dado que $\operatorname{Conv}(\Phi)$ não coincide com $\Phi$, parte de $\mathcal{P}$ está no interior de $\mathcal{P}^{\prime}$. 
Na segunda situação forma-se o polígono $K_{i j}: A_{i} A_{i+1} \cdots A_{j-1} A_{j}$. Vamos provar que $K_{i j}$ tem pelo menos uma boca. Pelo Teorema 9, há pelo menos duas orelhas não sobrepostas em $K_{i j}$. Por não haver sobreposição, as pontas das orelhas não ocorrem em $A_{i}$ e $A_{j}$, isto é, pelo pelo menos uma ponta ocorre em $A_{k}$ com $i<k<j$ (Figura 19). Obviamente a orelha formada no vértice $A_{k}$ de $K_{i j}$ é uma boca de $\mathcal{P}$. Isso demonstra o teorema.

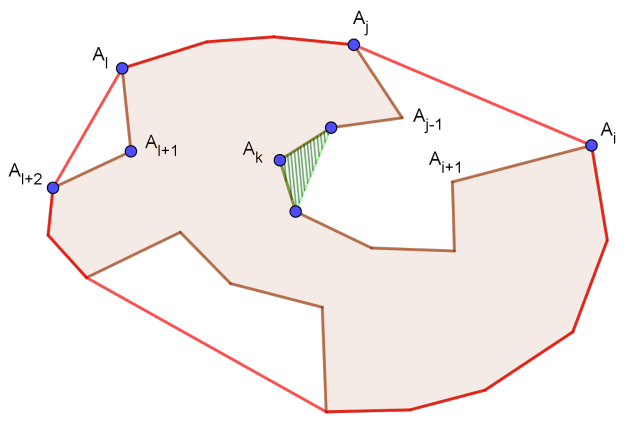

Figura 19: Visualização da ideia da demonstração do Teorema 13.

Na sequência iremos interpretar o Teorema da boca. Percebemos que pela definição de convexidade, se um polígono é convexo todas as suas diagonais devem ser internas, portanto o polígono não pode ter bocas ou qualquer outro tipo de vértice reentrante. O que o Teorema 13 nos ensina é que caso tenhamos um polígono que não contenha bocas, podemos garantir apenas com essa informação que ele é convexo. Obtemos, com isso, mais uma definição de convexidade para polígonos simples.

Definição 19 ( $5^{a}$. Definição de Polígono Convexo). Um polígono simples é convexo quando não contém nenhuma boca.

No seção anterior discutimos a generalização da noção de ângulo em polígonos simples. Notamos que a existência de uma boca em um polígono implica a existência de um ângulo reflexo no vértice da respectiva boca. Podemos, portanto, obter mais uma definição de polígono convexo

Definição 20 ( $6^{a}$. Definição de Polígono Convexo). Um polígono é convexo quando todos os seus ângulos internos são convexos.

A Definição 20 é uma caracterização pouco usual na educação básica. Uma exceção pode ser encontrada no livro Matemática: Contexto e Aplicaçôes de Luiz Roberto Dante, no qual apresentase uma caracterização de polígono convexo que nos remete à ideia de boca: "Um polígono é dito convexo quando todos os seus vértices apontam para fora."[7, p397], (Figura 20a). Além disso, geralmente nos livros didáticos quando é apresentado um desenho de um polígono não convexo, é quase sempre um exemplo de um polígono com uma boca (Figura 20).

Pela $1^{a}$ Definição de polígono convexo (Definição 5 ), um polígono convexo pode ter apenas diagonais internas. Não é certo, porém, que um polígono simples tendo todas as suas diagonais internas seja convexo. Esse é o conteúdo do próximo teorema. 


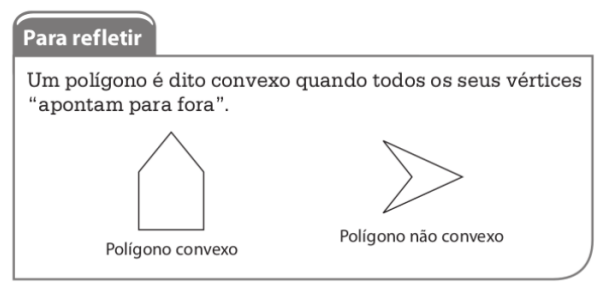

(a) FONTE:[7, p397]

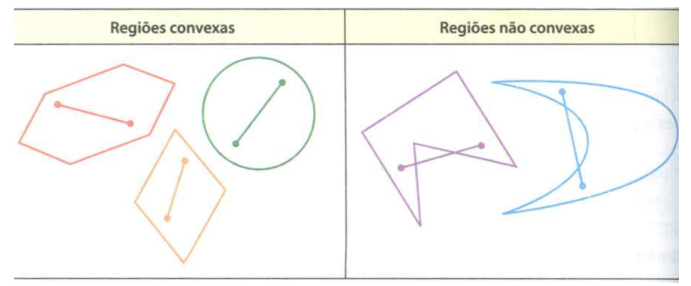

(b) FONTE: Editora Moderna, 2010 [13].

Figura 20: Exemplos de polígonos não convexos em livros didáticos.

Teorema 14. Quaisquer dois vértices não consecutivos de um polígono simples $\mathcal{P}$ determinam uma diagonal interna de $\mathcal{P}$ se, e somente se, $\mathcal{P}$ é um polígono convexo.

Demonstração. Primeira parte. Supondo que $\mathcal{P}$ não seja convexo. Pelo Teorema da Boca, existe uma sequência de três vértices $A, B$, e $C$ com $B$ reflexo. Então o segmento $A C$, exceto pelos pontos $A$ e $C$, está contido no exterior de $\mathcal{P}$ e, portanto, não determina uma diagonal interna.

Segunda parte. Supomos que exista um par de vértices não consecutivos $A$ e $B$ de $\mathcal{P}$ que não forma uma diagonal interna e que $\mathcal{P}$ seja um polígono convexo. Se $A B$ não é uma diagonal interna, então existe pelo menos um ponto de $A B$ que não pertence a $\Phi$ e $\mathcal{P}$ não é convexo. Esse absurdo mostra que quaisquer dois vértices não consecutivos formam uma diagonal interna.

Por conta do Teorema 14 podemos colecionar mais uma definição de convexidade para polígonos simples.

Definição 21 ( $7^{a}$. Definição de Polígono Convexo). Um polígono simples é convexo quando todas as suas diagonais são internas.

\section{Sugestões de aplicações à sala de aula}

Nessa seção discutiremos aplicações em sala de aula. A apresentação aqui terá como base o formalismo da seção anterior, porém apelaremos sempre que possível à intuição. O objetivo é sugerir ideias para o professor apresentar em sala de aula usando o conceito de convexidade.

\subsection{Geoplano e o fecho convexo}

Quando construímos um polígono simples no geoplano, percebemos que existem dois tipos de vértices:

1. Vértices em que o elástico fica tensionado para dentro do polígono.

2. Vértices em que o elástico fica tensionado para fora do polígono; 


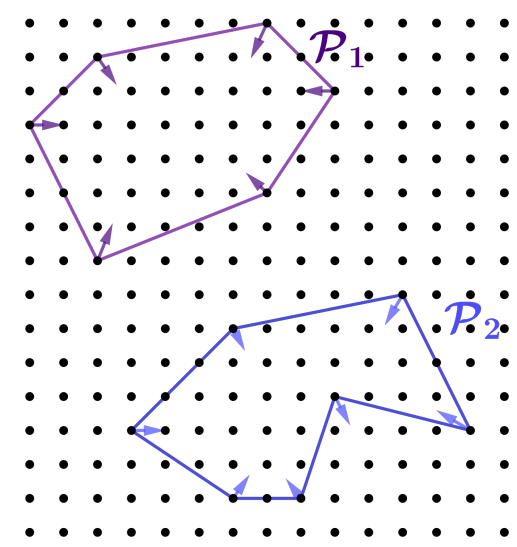

(a) Vértices reflexos e pontas no Geoplano.

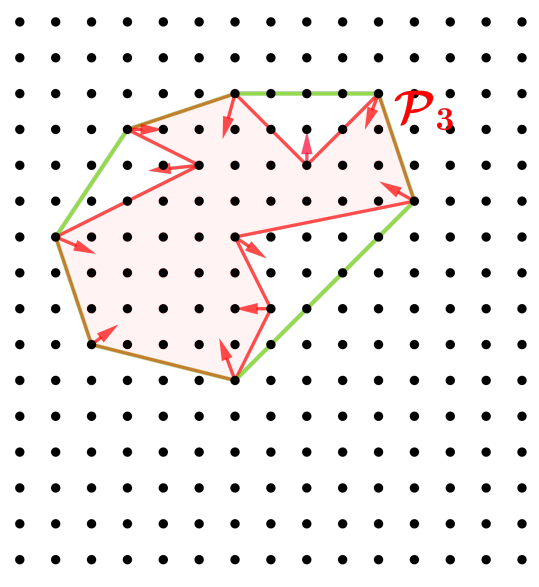

(b) Fecho convexo no Geoplano.

Figura 21: Convexidade no Geoplano.

Nos vértices do tipo 1, o elástico enrola-se na haste por fora do polígono, e nos do tipo 2 , enrolase por dentro (Figura 21). Os vértices do tipo 1 são pontas e os vértices do tipo 2 são vértices reentrantes.

$\mathrm{O}$ polígono $\mathcal{P}_{1}$ não contém nenhum vértice reflexo, i.e., só tem vértices do tipo 1 ; O polígono $\mathcal{P}_{2}$ tem um vértice reflexo, portanto não é convexo. No polígono $\mathcal{P}_{3}$ percebe-se que o fecho convexo apoia-se apenas em vértices do tipo 1, i. e., em pontas.

Na Figura 22a vemos um polígono simples e o contorno do seu fecho convexo. Sempre é possível, usando mais elásticos, dividir a região limitada pelo polígono inicial em polígonos convexos. Cada vértice das figuras parciais obtidas serão do tipo 1, para cada elástico, e teremos o cuidado para não haver sobreposições, ao menos entre lados, ou buracos no interior do polígono original (Figura $22 b)$.

Essa demonstração visual permite concluir que todo polígono simples pode ser triangularizado, já que podemos triangularizar cada um dos polígonos convexos obtidos.

\subsection{Circulação}

Imaginemos um ponto móvel $P$ percorrendo um polígono como na Figura 23. Há dois sentidos de percurso ao longo de $\mathcal{P}$, que chamamos de sentido horário e sentido anti-horário. Quando o sentido de percurso for o anti-horário, um observador no ponto móvel sempre verá o interior do polígono ao seu lado esquerdo. Quando o ponto móvel passa pelo vértice $A$ ou pelo $C$, o observador no ponto móvel gira a sua esquerda. Quando o ponto móvel passa pelo ponto $B$, o observador gira a sua direita. 


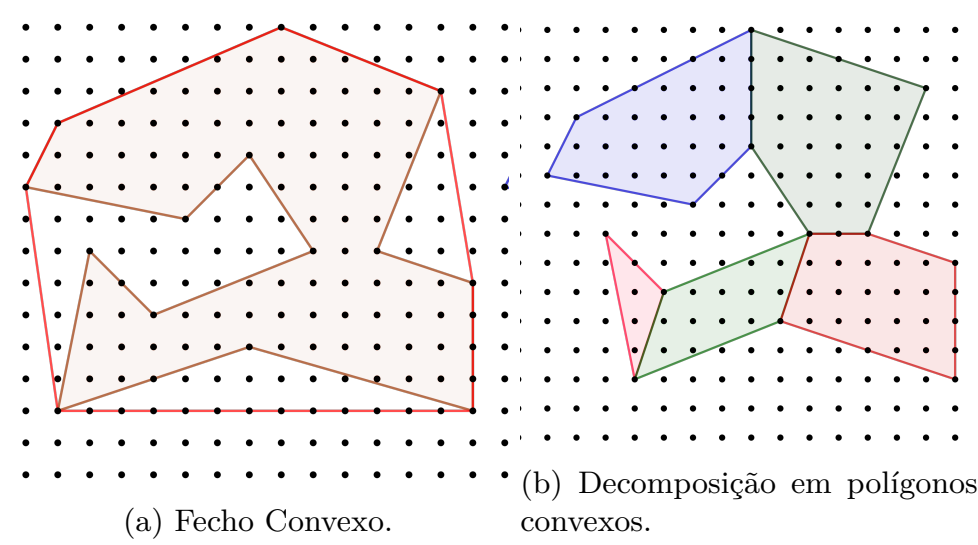

Figura 22: Demonstração visual da decomposição de um polígono simples.

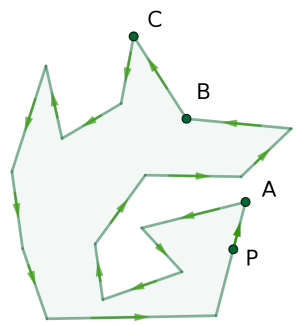

Figura 23: Percurso no polígono.

Percebe-se que os pontos $A$ e $B$ são vértices convexos e o ponto $B$ é um vértice reflexo. Podemos concluir visualmente, que em um percurso sobre um polígono convexo no sentido anti-horário, quando o observador no ponto móvel passa por um vértice, a mudança de direção é sempre através de um giro para a esquerda do observador.

\subsection{Visualização}

A visibilidade é uma interpretação direta da Definição 4, de subconjunto convexo do plano.

Definição 22. Seja $\Phi$ a região limitada pelo polígono simples $\mathcal{P}$ e $A \in \Phi$. O ponto $B$ é visível relativamente a $A$ se o segmento $A B$ está inteiramente contido em $\Phi$. Dizemos nesse caso que $A$ cobre o ponto $B$. Quando $A$ cobre todos os pontos de $\Phi$ diremos que $A$ cobre $\Phi$.

A Definição 22 admite que o segmento $A B$ em alguns casos possa roçar a fronteira do polígono. Ainda nesse caso estamos considerando que não há perda de visibilidade.

Reintrepretando a Definição 4, podemos reescrevê-la em termos de visibilidade:

Definição 23 ( $8^{a}$. Definição de Polígono Convexo). Um polígono $\mathcal{P}$ que limita uma região $\Phi$, é convexo quando qualquer ponto $A \in \Phi$, cobre $\Phi$. 
Em casos menos gerais, existem apenas alguns pontos dos quais toda a região limitada pelo polígono pode ser coberta. Para os triângulos, quadriláteros ou pentágonos simples, convexos ou não, sempre podemos achar pelo menos um ponto interno que cubra toda a região limitada pelo polígono (Figura 24).
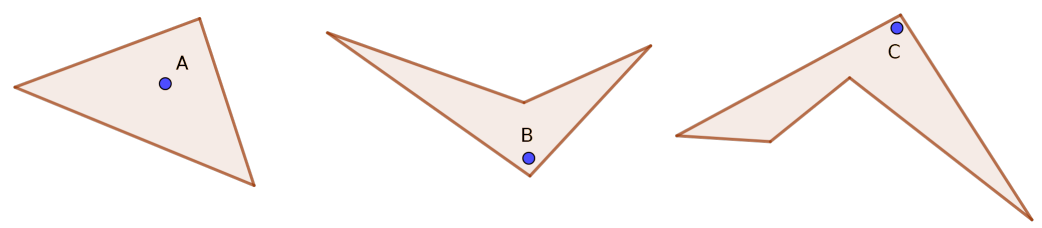

Figura 24: Visibilidade do triângulo, quadrilátero e pentágono simples.

Para polígonos simples com número de lados maior que ou igual a seis, essa propriedade não é garantida (Figura 25).

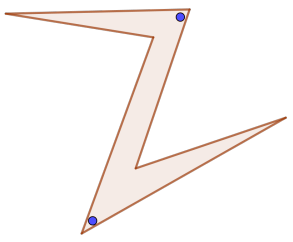

(a) Suficiente dois (b) Suficiente quatro pontos.

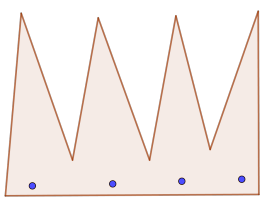

pontos.

Figura 25: Cobertura de polígonos.

Surge aqui uma curiosidade. Para um polígono simples $\mathcal{P}$ de $n$ lados, que limita a região $\Phi$, é possível obter um número mínimo de pontos fixos que dependa de $n$ tal que $\Phi$ possa ser totalmente coberto? A resposta é sim. Historicamente esse problema é conhecido como o Problema da Galeria de Arte e foi proposto por Victor Klee em 1973. Na linguagem de Klee os pontos fixos são guardas estacionários e $\Phi$ é uma planta de uma galeria de arte. O problema da galeria de arte consiste no seguinte: Qual o número mínimo de guardas suficientes para cobrir o interior de uma Galeria de Arte com $n$ paredes?. Esse interessante problema foi resolvido por Václav Chvátal em 1975. Para maiores informações consulte [2].

Para a sala de aula é importante apresentar a convexidade dos polígonos simples por meio da visibilidade. Imagine um guarda com uma lanterna potente vigiando um andar de um shopping, cuja planta é uma polígono convexo, conforme Figura 26. 


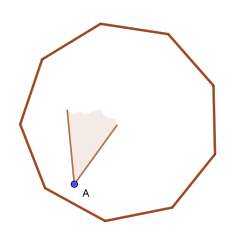

Figura 26: Polígono convexo.

Desconsiderando os obstáculos como móveis, pilares, o guarda consegue iluminar qualquer ponto da planta com sua superlanterna.

\section{Considerações finais}

Os resultados apresentados neste trabalho forneceram várias caracterizações de polígonos convexos, mas somente duas ou três delas são utilizadas na educação básica. A mais comum das caracterizações é a que diz ser necessário que um segmento esteja totalmente contido na região limitada pelo polígono, se seus extremos estejam nela. Essa definição é utilizada com frequência por ser mais intuitiva e se adequar a um primeiro contato com polígonos convexos. Perceber que as várias definições apresentadas nos livros são equivalentes não é algo trivial. No presente trabalho essa lacuna é preenchida ao serem provadas as equivalências entre as diversas caracterizações de polígonos convexos. Apresenta-se um texto que, de certo modo, complementa e amplia os tópicos sobre convexidade abordados em livros didáticos. Embora os resultados que foram demonstrados sejam de alto significado intuitivo, não são consequências imediatas do modelo axiomático considerado e tradicionalmente não surgem nos primeiros textos de geometria dedutiva. Por essa razão, os livros de geometria disponíveis aos estudantes de licenciatura no Brasil, que serão os futuros professores da educação básica, não tratam desses resultados devido às dificuldades oferecidas nas demonstrações, que exigem maior intimidade com o método axiomático. Tais habilidades ainda não estão presentes na maioria dos estudantes, pois o curso de geometria dedutiva, geralmente, é utilizado para ensinar o método axiomático. Por constituir uma extensão natural aos resultados obtidos em um primeiro curso de geometria dedutiva, acreditamos que os resultados aqui apresentados possam ser úteis a quem se interesse por geometria.

\section{Referências}

[1] ALlen, F. et al. Geometry, Student's Text, Part I, Unit I3. Yale University Press, 1960.

[2] ANDRÉ, L. do N. Convexidade em figuras geométricas planas. Dissertação de Mestrado, Joinville, 2018. Disponível em <http://www.profmat-sbm.org.br/dissertacoes/?polo=\&titulo= \&aluno=Luciano +do+nascimento+andre $>$. Acesso em: 08 set. 2018.

[3] BARBOSA, J. L. M. Geometria euclidiana plana. 10 ${ }^{a}$ ed. Rio de Janeiro: SBM, 2006. (Coleção do Professor de Matemática).

[4] BERG, M. de B. et al. Computational Geometry: Algorithms and Applications. Berlin: Springer-Verlag, 2008.

[5] BIANCHINI, E. Matemática Bianchini 8 $8^{a}$ ed. são Paulo: Moderna, 1961. 4 v. 
[6] COURANT, R.; ROBBINS, H. O que é matemática?: Uma abordagem elementar de métodos e conceitos. Rio de Janeiro: Ciência Moderna, 2000.

[7] DANTE, L. R. Matemática: Contexto e aplicações. $1^{a}$ ed. São Paulo: Ática, 2010. 3 v.

[8] GIOVAnNI Jr., J. R.; CASTRUCCI, B. A conquista da matemática, 6o ano. Ed. Renovada. são Paulo: FTD, 2009.

[9] LEIVAS, J. C. P. Imaginação, intuição e visualização: a riqueza de possibilidades da abordagem geométrica no currículo de cursos de licenciatura de matemática.. Tese de Doutorado, Curitiba, 2009. Disponível em <https://acervodigital.ufpr.br/handle/1884/19925>. Acesso em: 28 mar. 2019.

[10] LIMA, E. L."A soma dos ângulos (internos ou externos) de um polígono (convexo ou não)." Revista do Professor de Matemática, 19. S.B.M, 1990.

[11] LIMA, E. L.“Qual é mesmo a definição de polígono convexo?." Revista do Professor de Matemática, 21. S.B.M, 1991.

[12] LIMA, E. L. Matemática e ensino. $3^{a}$ ed. Rio de Janeiro: SBM, 2007. (Coleção do Professor de Matemática).

[13] EDITORA MODERNA. Conexões com a matemática. Editora responsável Juliane Matsubara Barroso. Obra coletiva concebida, desenvolvida e produzida pela Editora Moderna. $1^{a}$ ed. são Paulo: MODERNA. 2010.

[14] O'ROURKE, Joseph. Art gallery theorem and algorithms. New York: HOxford University Press Inc., 1987.(International Series of Monographs on Computer Science).

[15] O'ROURKE, Joseph; DEVADOS, Satyan L. Discrete and Computational Geometry. New Jersey: Princeton university press, 2011.

[16] PAIVA, M. Matemática: Paiva. $3^{a}$ ed. São Paulo: Moderna, 2015.

[17] POGORELOV, A. V. Geometria Elemental. Moscou: Editorial MIR, 1974.

[18] REZENDE, E. Q. F.; QUEIROZ, M. L. B. de. Geometria euclidiana plana e construções geométricas. São Paulo: Editora da Unicamp, 2008.

[19] TOUSSAINT, G. T. Anthropomorphic polygons. American Mathematical Monthly, v. 98, n.1, pp31-35, 1991. Disponível em <http://www-cgrl.cs.mcgill.ca/ qodfried/>. Acesso em: 31 mar. 2019.

[20] YAGLOM, A. M.; BOLTYANSKII, V. G. Convex Figures. New York: Holt Rinehart and Winston, 1961.

Luciano André EEB Antonio Milanez Netto - Criciúma, SC <luciano.nasc.andre@gmail.com>

Rogério de Aguiar UDESC - Joinville, SC <rogerville2001@gmail.com> 